\title{
Is There a Difference Between the Readabilities of Informed Consent Forms Used for Procedures in the Emergency Services of State and University Hospitals in Turkey?
}

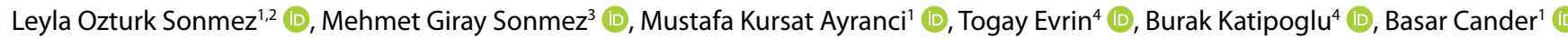 \\ 'Department of Emergency Medicine, Necmettin Erbakan University Meram School of Medicine, Konya, Turkey \\ 2Department of Physiology, Selcuk University School of Medicine, Konya, Turkey \\ ${ }^{3}$ Department of Urology, Necmettin Erbakan University Meram School of Medicine, Konya, Turkey \\ ${ }^{4}$ Department of Emergency Medicine, Ufuk University School of Medicine, Ankara, Turkey
}

Cite this article as: Ozturk Sonmez L, Sonmez MG, Ayranci MK, Evrin T, Katipoglu B, Cander B. Is There a Difference Between the Readabilities of Informed Consent Forms Used for Procedures in the Emergency Services of State and University Hospitals in Turkey? Eurasian J Emerg Med. 2018; 17 (4): 193-8.

\section{Abstract}

Aim: The aim of the present study was to evaluate the readability levels of informed consent forms (ICFs) used for procedures in the emergency services of state and university hospitals by comparing through readability formulas.

Materials and Methods: ICFs used in emergency medicine clinics in different university and state hospitals in Turkey were collected, and forms that were the same were included in the evaluation only once. A total of 32 ICFs, with 15 from university hospitals and 17 from state hospitals, were evaluated. Average word number, syllable number, and words with syllable number of four and above were calculated. Different formulas were used to determine readability levels.

Results: Although the readability of ICFs used in university hospitals was found to be better than those in state hospitals, the readability levels of the ICFs for both groups were detected to have medium difficulty according to the Atesman formula, very difficult according to the Flesch-Kincaid formula, difficult according to the Gunning-Fog formula, and at high school level according to the Bezirci-Yilmaz formula.

Conclusion: In conclusion, the readability rates of emergency procedure ICFs in both state hospitals and university hospitals were detected to be rather low according to the present study. The education level of our country and the local environment should be considered while preparing these ICFs.

Keywords: Emergency medicine, informed consent form, readability, understandability

\section{Introduction}

The negative perception of being ill causes the need of being aware of the phases the patients will go through. People should acquire, encode, preserve, and process information to better understand the intervention phase. It should also be considered that reading a text is an activity, including caution, memory, understanding, and knowledge. Memory is the amount of information that can be processed, formed,

ORCID IDs of the authors: L.O.S. 0000-0003-0201-4468; M.G.S. 0000-0003-46157348; M.K.A. 0000-0002-7196-0856; T.E. 0000-0002-83064303; B.K. 0000-0002-7950-824X; B.C. 0000-0003-1035-1907.

This study was presented in $5^{\text {th }}$ Intercontinental Emergency Medicine and International Critical Care and Emergency Medicine Congress, Antalya, Turkey.

Corresponding Author: Mehmet Giray Sonmez e-mail: drgiraysonmez@gmail.com 
and recorded by humans. In this regard, the reader should be able to read a text well to be able to understand it (1-4).

For the presentation of some quantitative data on texts, readability provides information on whether the text is easily understandable by the reader at a certain level through the characteristics of the syllables, words, and sentences in that language. Factors influencing readability are the word length, word frequency, multi syllable number, sentence length, ambiguous word number, and syllable number. The readability of the sentence decreases as the number of words in a sentence increases (2-4). There are many formulas developed for readability analysis (5-8).

Acting in accordance with the standard applications determined in the emergency medicine field and knowing the occupational legislation are rather important. Thus, informed consent is one of the important aspects of ethical medical practice. Making an intervention without informed consent may mean negligence or malpractice and may cause a legal action, maltreatment, and even attack against the doctor $(2,3)$.

The aim of the present study was to evaluate the readability levels of informed consent forms (ICFs) used for procedures in the emergency services of state and university hospitals by comparing through readability formulas.

\section{Materials and Methods}

The present study was conducted using a descriptive scanning method based on a document review from April to September 2017. We contacted 14 hospitals in Konya, Ankara, and Istanbul, which are large cities in Turkey, through phone and e-mail. ICFs used in emergency clinics of four different universities and five state hospitals, with two training and research hospitals and three state hospitals, the consent forms of which could be reached, were collected. A total of 126 ICFs were gathered. There were 61 consent forms from universities and 65 from state hospitals. ICFs included tube thoracostomy, endotracheal intubation, blood products transfusion, cardioversion and defibrillation, intramuscular injection, intravenous injection, closed reduction of fractures and dislocations, small surgical interventions, lumbar puncture, paracentesis, peritoneal lavage, fibrinolysis, central venous catheterization, sedation, thoracentesis, and tracheostomy procedures. ICFs that were exactly the same were included in the evaluation only once. A total of 32 ICFs, with 15 from university hospitals and 17 from state hospitals, were evaluated. The study was designed in conformity with the Declaration of Helsinki.

Information text available in these consent forms was copied and transferred to Microsoft Word (Microsoft, Redmond, WA, USA) program and was calculated manually using the Microsoft Excel (Microsoft) program. Average word number, syllable number, and words with syllable number of four and above were calculated. The Atesman (5) and Bezirci-Yilmaz (6) formulas defined for determining the readability level of Turkish texts and the Gunning-Fog (8) and Flesch-Kincaid (7) formulas for measuring the general readability level were used for calculating the readability level of consent forms.

\section{Atesman readability formula}

The Atesman readability formula is based on the length of the word and sentence.

Readability Score is calculated as $198.825-40.175 \times$ (total syllables/total words) $-2.610 \times$ (total words/total sentences). It is understood that the readability level of a text is considered easier when it comes closer to 100 and harder when it comes closer to 0 according to the Atesman formula.

\section{Bezirci-Yilmaz readability formula}

The Bezirci-Yilmaz readability formula was developed based on the sentence length and syllable number in words, characteristics in different formulas developed until today, and statistical characteristics of the Turkish language. According to this formula, the readability difficulty of the texts increases when the sentences in the texts are longer. Similarly, an increase of the syllable number in the words makes the readability of that word and the sentences harder most of the time.

The Bezirci-Yilmaz readability formula is calculated as:

Where, $\sqrt{\operatorname{AWNx}((\mathrm{S} 3 \times 0.84)+(\mathrm{S} 4 \times 1.5)+(\mathrm{S} 5 \mathrm{x} 3.5)+(\mathrm{S} 6 \times 6.26 .25))}$

AWN: average word number,

S3: number of words with an average of three syllables,

S4: number of words with an average of four syllables,

S5: number of words with an average of five syllables,

S6: number of words with an average of six or more syllables.

The result acquired from this formula explains which class level a text addresses to according to the education system in our country. The education system shows elementary school education level for classes 1-8, secondary (high) school education for classes 9-12, bachelor's degree for classes 12-16, and academic education level for classes $\geq 16$.

\section{Flesch-Kincaid formula}

The length of the words and sentences is determined according to the following formulas:

Readability $=(0.39 \times$ sentence length $)+(1.18 \times$ word length $)-15.59$, World length=syllable number/word number, Sentence length=word number/sentence number.

Syllable number is divided into the word number for the word length, and word number is divided into sentence number for sentence length. The text is evaluated as easy when the syllable number of each word is closer to 1 and as difficult when the syllable number increases up to 10. The same operation is valid for the sentence. The text is evaluated as easy when the word number decreases to 1 and as difficult when it is more than 10 .

\section{Gunning-Fog Index formula}

There are two important aspects in the Gunning's formula. These are words containing three or more syllables and the average number of words used in sentences. These are calculated as follows: 
Table 1. Readability intervals of the readability formulas used in our study

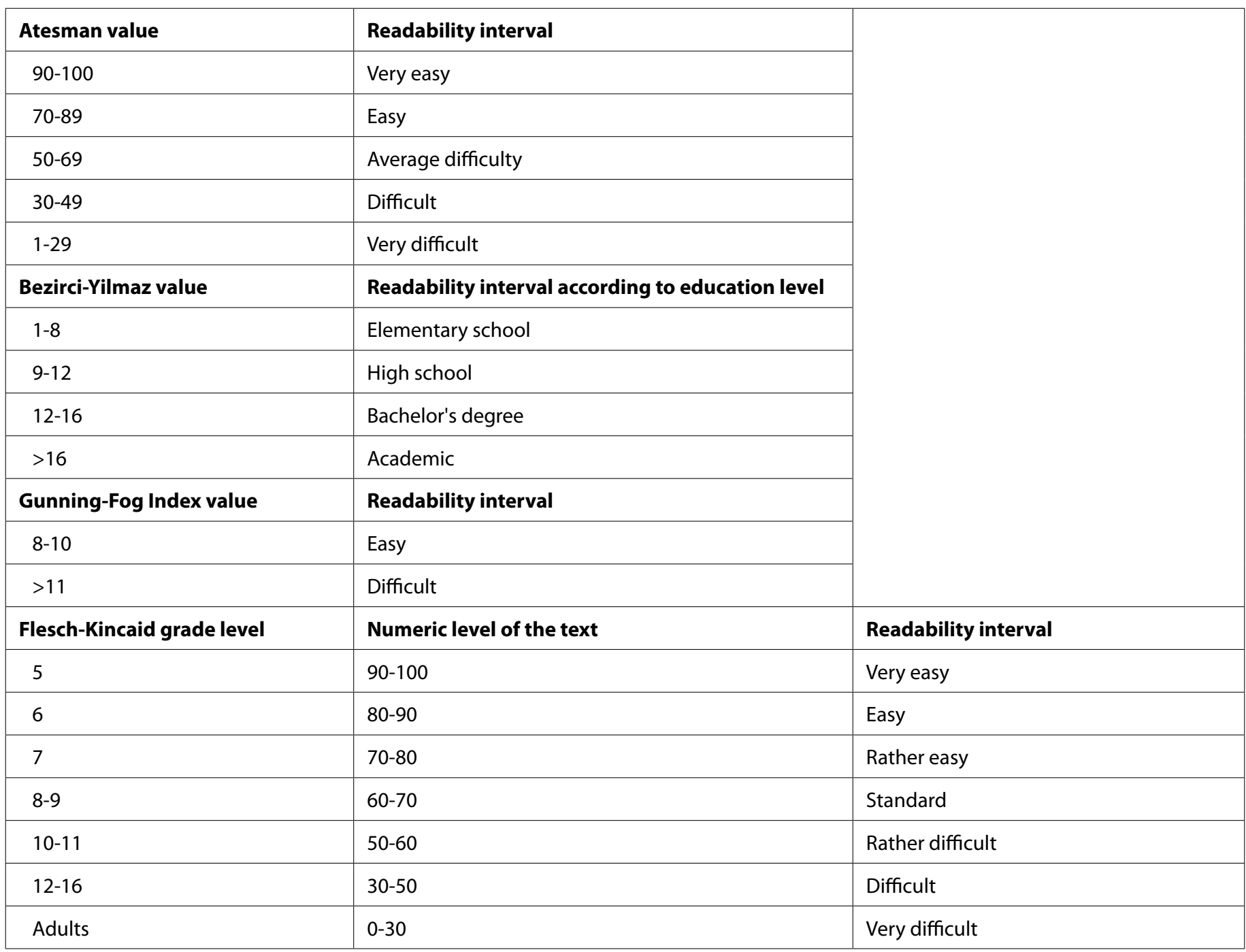

Fog Index $=0.4 \times$ (word rate with three syllables+average number of words),

Word rate with three syllables $=$ (number of words with three or more syllables/remaining number of words) $\times 100$,

Average number of words=word number/sentence number. It is an easy text if the result is between 8 and 10 and a difficult text above 11 . Table 1 shows the readability intervals of the readability formulas used in the study.

\section{Statistical analysis}

Dataset analyses were made using the Statistical Package for Social Sciences volume 23.0 (IBM Corp.; IL, Chicago, USA) program. Continuous variables are presented as mean and standard deviations. Normality of distribution of constant numeric variables was made using the Kolmogorov-Smirnov test. Independent T-test and MannWhitney $U$ test was used for analyzing two independent groups. $A$ $\mathrm{p}<0.05$ was accepted as statistically significant.

\section{Results}

Informed consent forms were used for emergency tube thoracostomy, endotracheal intubation, blood products transfusion, cardioversion and defibrillation, intramuscular injection, intravenous injection, closed reduction of fractures and dislocations, small surgical interventions, lumbar puncture, paracentesis, peritoneal lavage, fibrinolysis, central venous catheterization, sedation, thoracentesis, and tracheostomy.

The sentence, word, letter, character, and syllable numbers were significantly lower in ICFs used in university hospitals than in those in state hospitals $(p<0.001, p=0.003, p<0.001, p<0.001$, and $p<0.001$, respectively).

When readability formulas of both groups were evaluated, it was detected that the ICFs used in university hospitals were more readable according to the Atesman, Gunning-Fog, and Flesch-Kincaid formulas and very readable at a lower education level according to the BezirciYilmaz formula ( $p=0.01, p<0.001, p=0.04$, and $p=0.89$, respectively). 
Table 2. Numerical values for the consent forms used in emergency service clinics of state and university hospitals in Turkey.

\begin{tabular}{|l|c|c|c|}
\hline Parameters & $\begin{array}{c}\text { University } \\
\text { hospital } \\
\text { ICFs }\end{array}$ & $\begin{array}{c}\text { State } \\
\text { hospital } \\
\text { ICFs }\end{array}$ & p \\
\hline Sentence number & $56.5 \pm 5.8$ & $76.8 \pm 56.6$ & $<0.001$ \\
\hline Word number & $610 \pm 135$ & $746 \pm 99$ & 0.003 \\
\hline Letter number & $3753 \pm 456.4$ & $5038 \pm 687$ & $<0.001$ \\
\hline Character number & $4862 \pm 668$ & $6099 \pm 808$ & $<0.001$ \\
\hline Syllable number & $1612 \pm 194.5$ & $2182 \pm 295$ & $<0.001$ \\
\hline $\begin{array}{l}\text { Words with an average } \\
\text { syllable number of four } \\
\text { and above }\end{array}$ & $138.9 \pm 32.8$ & $227 \pm 32$ & $<0.001$ \\
\hline Flesch-Kincaid & $20.3 \pm 3.18$ & $22.6 \pm 0.7$ & 0.014 \\
\hline Gunning-Fog & $13.6 \pm 1.8$ & $15.9 \pm 0.95$ & $<0.001$ \\
\hline Atesman & $62.7 \pm 9.8$ & $56.6 \pm 4.6$ & 0.04 \\
\hline Bezirci-Yilmaz & $10 \pm 1.12$ & $10.8 \pm 1.1$ & 0.89 \\
\hline ICFs: informed consent forms & & & \\
\hline
\end{tabular}

Although the readability of the consent forms used in university hospitals was found to be better than those in state hospitals, the readability levels of the consent forms for both groups were detected to have medium difficulty according to the Atesman formula, very difficult according to the Flesch-Kincaid formula, difficult according to the Gunning-Fog formula, and at high school level according to the Bezirci-Yilmaz formula. Table 2 shows the numerical values for readability parameters of both groups.

\section{Discussion}

Readability is a language concept that appeared in the United States at the beginning of the 19th century. For presentation of some quantitative data on texts, readability provides information on whether the text is easily understandable by the reader at a certain level through the characteristics of the syllables, words, and sentences in that language (2). Informed consent process ensures that patients are properly informed of all aspects of the procedures. Obtaining informed consent is considered a responsible conduct (2). Most written consent forms are lengthy and difficult to read for patients, particularly those with low health literacy. Consent forms used for procedures are known to be more difficult to understand because of the increased disclosure requirements, which is often too much information for the average reader to process at once (9-11). Thus, it was concluded that there was a relationship between education and understanding levels in general according to previous studies made. Stating the target education level for a text provides a certain rate of information on its understandability. Consent forms for emergency procedures should be understandable by the patient population at every education level $(2,3)$. In addition, ICFs typically include complex information regarding procedures, contain several unfamiliar medical terms, and are often required to include difficult to understand legal terminology. As a result, it is very common for patients to have difficulty understanding the information written in the consent form before agreeing to patients in the procedures, leaving many to wonder if patients are actually providing informed consent (11-13).

The National Institutes of Health and the American Medical Association suggest that the readability of patient materials should be at $\leq 6^{\text {th }}$ grade reading level as the average readability level of adults in the USA is at $8^{\text {th }}$ grade level $(14,15)$.

A recent review of written consent forms revealed that most are currently written at a 10th grade reading level or higher across all medical specialties (16). Readability levels of ICFs were measured in different countries for different medical branches before. A study made in the USA reported that invasive operation ICFs were written at an average of $15^{\text {th }}$ grade level (i.e., a third year of college) (16).

A study in 2014 detected that two-thirds of the society in Turkey has an inadequate level of health literacy (17). While the average education level of the whole population $>15$ years old is reported as 7.18 years in Turkey according to the 2010 data, the average education level of only females $>15$ years old is reported as 6.33 years (18).

Consent documents that are written at a high-grade level may create additional risks for patients due to lack of understanding. To ensure that patients are fully informed of all aspects of the procedure and completely understand what is expected when agreeing to participate, it is important to ensure that consent forms are written in plain language, that is, writing that is clear and easy to understand the first time the participant reads or hears it (9).

Mariscal-Crespo et al. (19) reported that ICFs used in public hospitals are analyzed globally in Spain, and it was shown that $62.4 \%$ had "somewhat difficult," 23.4\% had "normal," and 13.4\% had "very difficult" readability. Gargoum and Keeffe (20) evaluated the information forms used for endoscopic interventions in Ireland and reported that only $62 \%$ of the forms are easy to read, and $57 \%$ are at the reading level for 13-15 years old.

Norberto et al. (21) evaluated the ICFs of different branches, such as urology and cardiovascular surgery, and reported that the ICFs do not have an adequate level of readability although there is a difference in readability among these branches.

In our study, consent forms of both groups did not have an adequate level of readability, which was in line with previous studies. Readability levels of both groups were hard according to the Atesman, FleschKincaid, and Gunning-Fog formulas and at high school level according to the Bezirci-Yilmaz formula.

Vučemilo et al. (22) reported that the consent forms used in Croatia are at 16th grade level, there is no difference in readability among the consent forms used in internal medicine and surgery, and readability levels of ICFs do not change with the degree of the health institution. 
In contrast to their study, in our study, although it was detected that the consent forms used in university hospitals were detected to have higher readability, readability range of both groups classified according to readability formulas was similar.

Boztas et al. (2) compared the readability of the anesthesia ICFs used in state, training and research, and university hospitals in Turkey and reported that ICFs used in university hospitals have higher readability than those in state hospitals according to the Gunning-Fog formula and are readable at a lower education level according to the Atesman formula. Similar to their study, in our study, it was detected that ICFs used in university hospital were more easily readable than those in state hospitals according to the Atesman, Gunning-Fog, and FleschKincaid formulas and readable at a lower education level according to the Bezirci-Yilmaz formula.

We think that better readability level in emergency clinics of university hospitals where more complex procedures are applied than state hospitals would be more advantageous for the patients.

Previous studies reported that these forms are made easier with marked texts and diagrams so that ICFs can be understood and remembered more easily, and these video-supported forms are more understandable and rememberable (23).

Readability level of ICFs made easier and enriched by visual information, such as videos and diagrams, would increase ratios for understanding the procedure and remembering its possible risks. Thus, the language used on ICFs should be at a reading level suitable for the target audience, contain a proper and readable text style, and contain visual presentation as much as possible. Generally, the first few lines are very important for the readability of the text because these have a critical importance for the reader to continue reading the consent form.

Use of interesting samples and stories for the reader, forming a logical structure with important points at the beginning of each paragraph, and ordinary use of the language are other general suggestions.

\section{Conclusion}

Informed consent forms are commonly used in emergency procedures and change in different centers. Consent forms are not adapted to the local environment where the intervention will be made. If the patient does not understand the aim of the intervention and believes that the application may provide benefit, then there is a "therapeutic misunderstanding." Although readability tests cannot provide certain results on the understandability of the text, they provide some ideas on the text level. As a result, the readability rates of emergency procedure consent forms in both state hospitals and university hospitals were detected to be rather low according to the present study. The education level of our country and the local environment should be considered while preparing these consent forms.
Ethics Committee Approval: Authors declared that the research was conducted according to the principles of the World Medical Association Declaration of Helsinki "Ethical Principles for Medical Research Involving Human Subjects", (amended in October 2013).

Informed Consent: Written informed consent was not necessary because no patient data has been included in the manuscript.

Peer-review: Externally peer-reviewed.

Author Contributions: Concept - L.O.S., M.G.S.; Design - L.O.S., M.G.S.; Supervision - L.O.S., M.G.S., M.K.A., T.E., B.K., B.C.; Resources - L.O.S., M.G.S., M.K.A., T.E., B.K., B.C.; Materials - L.O.S., M.G.S.; Data Collection and/or Processing - L.O.S., M.G.S., M.K.A., T.E., B.K., B.C.; Analysis and/or Interpretation - L.O.S., M.G.S., M.K.A., T.E., B.K., B.C. ; Literature Search - L.O.S., M.G.S., M.K.A.; Writing Manuscript - L.O.S., M.G.S.; Critical Review - L.O.S., M.G.S., M.K.A., T.E., B.K., B.C.

Conflict of Interest: The authors have no conflict of interest to declare.

Financial Disclosure: The authors declared that this study has received no financial support.

\section{References}

1. Meneguin S, Aparecido Ayres J. Perception of the informed consent form by participants in clinical trials. Invest Educ Enferm. 2014; 32: 97-102.

2. Boztas N, Ozbilgin S, Ocmen E, Altuntas G, Ozkardesler S, Hancı V, et al. Evaluating the Readibility of Informed Consent Forms Available Before Anaesthesia: A Comparative Study. Turk J Anaesthesiol Reanim. 2014; 42: 140-4. [CrossRef]

3. Sonmez MG, Kozanhan B, Ozkent MS, Ecer G, Boğa MS, Demirelli E, et al. The evaluation of the readability of informed consent forms used for urology: Is there a difference between open, endoscopic and laparoscopic surgery? Turk J Surg. 2018, 28: 1-5.

4. Hadden KB, Prince LY, Moore TD, James LP, Holland JR, Trudeau CR. Improving readability of informed consents for research at an academic medical institution. J Clin Transl Sci. 2017; 1: 361-5. [CrossRef]

5. Atesman E. Measuring readability in Turkish. A.U. Tomer Language Journal. 1997; 58: 171-4.

6. Bezirci B, Yilmaz AE. A software library for measurement of readability of texts and a new readability metric for turkish. DEU FMD. 2010; 12: 49-62.

7. Flesch R. A new readability yardstick. J Appl Phycol. 1948; 32: 221-33. [CrossRef]

8. Gunning R, editor. The Technique of Clear Writing. New York: McGrawHill International Book Co; 1952.

9. Hadden KB, Prince LY, Moore TD, James LP, Holland JR, Trudeau CR, et al. Improving readability of informed consents for research at an academic medical institution. J Clin Transl Sci. 2017; 1: 361-5. [CrossRef]

10. Office of Human Research Protections. Informed consent. Washington, DC: US Department of Health and Human Services, 2016 (cited 2017 June 1). Available from: URL: http://www.hhs.gov/ohrp/policy/consent/index.html

11. Manta CJ, Ortiz J, Moulton BW, Sonnad SS. From the patient perspective, consent forms fall short of providing information to guide decision making. J Patient Saf. 2016 Aug 3. doi: 10.1097/PTS.0000000000000310. [Epub ahead of print] [CrossRef]

12. Hochhauser M. Consent forms: not easy to read. Applied Clinical Trials. 2007; 16: 74.

13. Sherlock A, Brownie S. Patients' recollection and understanding of informed consent: a literature review. ANZ J Surg. 2014; 84: 207-10. [CrossRef]

14. Eltorai $A E$, Sharma P, Wang J, Daniels AH. Most American academy of orthopaedic surgeons' online patient education material exceeds 
average patient reading level. Clin Orthop Relat Res. 2015; 473: 1181-86. [CrossRef]

15. Eltorai AE, Ghanian S, Adams CA Jr, Born CT, Daniels AH. Readability of patient education materials on the American association for surgery of trauma website. Arch Trauma Res. 2014; 3: e18161. [CrossRef]

16. Larson E, Foe G, Lally R. Reading level and length of written research consent forms. Clin Trans Sci. 2015; 8: 355-6. [CrossRef]

17. Tanriover MD, Yildirim HH, Ready FND, Cakir B, Akalin HE. Turkey Health Literacy Survey. December 2014. Available from: URL: http://www.sagliksen. org.tr/cdn/uploads/gallery/pdf/8dcec50aa18c21cdaf86a2b33001a409.pdf.

18. Barro R, Lee JW. Educational Attainment Dataset. 2011. Available from: URL: http://www.barrolee.com/ 2011.

19. Mariscal-Crespo MI, Coronado-Vázquez MV, Ramirez-Durán MV. Global analysis of the readability of the informed consent forms used in public hospitals of Spain. Rev Calid Asist. 2017; 32: 200-8. [CrossRef]
20. Gargoum FS, O'Keeffe ST. Readability and content of patient information leaflets for endoscopic procedures. Ir J Med Sci. 2014; 183: 429-32. [CrossRef]

21. Norberto EMS, Go'mez-Alonso D, Trigueros JM, Quiroga J, Gualis J, Vaquero C. Legibilidad del consentimiento informado quirurgico en Espana. Cir Esp. 2014; 92: 201-7. [CrossRef]

22. Vučemilo L, Borovečki A. Readability and Content Assessment of Informed Consent Forms for Medical Procedures in Croatia. PLoS One. 2015 Sep 16. doi: 10.1371/journal.pone.0138017. [Epub ahead of print] [CrossRef]

23. Shukla AN, Daly MK, Legutko P. Informed consent for cataract surgery: patient understanding of verbal, written, and videotaped information. J Cataract Refract Surg. 2012; 38: 80-4. [CrossRef] 